\title{
Exploring Polytechnic Students' Awareness of Safety Equipment and Precautions for Sustainable Working Environment in School Workshops
}

\author{
Bello Birchi Abdullahi \\ Department of Technical Education, College of Science and Technology, Hassan Usman Katsina Polytechnic, Katsina, Nigeria \\ Email address: \\ bellobirchi@gmail.com, bellobirchi@yahoo.com \\ To cite this article: \\ Bello Birchi Abdullahi. Exploring Polytechnic Students' Awareness of Safety Equipment and Precautions for Sustainable Working \\ Environment in School Workshops. International Journal of Science, Technology and Society. Vol. 5, No. 6, 2017, pp. $210-213$. \\ doi: $10.11648 /$ j.ijsts.20170506.16
}

Received: September 22, 2017; Accepted: October 14, 2017; Published: January 11, 2018

\begin{abstract}
This study explored polytechnic students' awareness of workshop safety precautions and sought to ascertain whether students' awareness of safety influenced the lack of rampant report of accidents during workshop practices. A total of 130 National Diploma Engineering students participated in the survey, who filled out questionnaire with 15 items measuring awareness of workshop safety precautions. Descriptive statistics was used to analyze the data. The results showed that a majority of students have between moderate to high level of awareness of workshop safety precaution except in 3 items where students have between low and zero level awareness. Furthermore, the results showed 3 items with high mean scores of 3.09, 3.24 and 3.01 respectively. These items were; the type of floor to be used in the workshop; type of protective clothing that should be worn in the workshop, and that students should never use any tool or machine until they knew how to use it." This meant that, students indicated high level of awareness of safety consideration in the stated items compared to others. The overall result indicates that students have quite a high level of awareness of workshop safety. The result further revealed that students' high level of awareness on safety has influenced the environmentally safe working condition in the polytechnic workshops.
\end{abstract}

Keywords: Safety Awareness, Safety Equipment, Workshop Practices

\section{Introduction}

There are many things over which students and instructors have no control and for which they are not responsible, but they are responsible for how they respond to circumstances (Griffin et al., 1995). Likewise, their lives and safety are no one's responsibility to safeguards but their own responsibility. The goal of workshop safety campaign is to increase student awareness, without creating overwhelming anxiety about situations they may encounter as student interns, and to develop basic workshop safety habits which they can readily use to remember in challenging situations.

Owing to the nature of today's current students' placements, most students begin with limited background and skills to deal with difficult safety circumstances. Many new students enroll into technical courses with limited knowledge and training regarding safety issues as they relate to workshop based practice. The issue of potential danger is one that you should consciously bring to your daily awareness as you begin your journey as a student or instructor to the workshop. Therefore, it is in everyone's best interest to be vigilant about the workshop surroundings and to have a plan at all times should they be confronted with danger. Learning a set of achievable interventions aimed at recognizing, managing, or avoiding dangerous situations is important at all times (Fernandez, 1995). A final thought involves maintaining your safety with regard to your health and wellbeing.

This research was galvanized by the sentiment and conviction that safety awareness is fundamental to sustainable working environment in school workshop. The same sentiment was voiced by the Workplace Safety and 
Insurance Board- Ontario (2001) to lunch the 7 things you would better know under the "young worker awareness program". The Workplace Safety Insurance Board also emphasized that, there are hazards in every working place and therefore, it is not enough for young people to identify the hazards in their workplace, but they need to be trained to recognize, assess, and control the hazards they find in their working place. It is important that student and instructors all be aware of the universal safety precautions and as well considered themselves becoming immune from exposure to potential health hazards.

\section{Statement of the Problem}

Given the enormous importance of workshop safety in sustaining a safe working environment, it is paramount to know what students understand about workshop safety or whether they are familiar with it at all. Their awareness and understanding of what it constitutes is crucial to ensuring a safe working environment. Yet, research efforts in assessing this awareness and understanding are acutely lacking. There was basically no research found that directly examined students' awareness on workshop safety equipment/precaution especially in Nigerian tertiary institutions. Only a few have looked at the attitudinal aspects of students' safety in the workshop, and explained the value and need for safety precaution in the workshop with no attempt to assessing students' awareness. This study was prompted by the acute lack of research in workshop safety awareness involving end users, particularly Nigerian Polytechnic students who are daily users of workshop. It was premised upon the idea that end user awareness is an important foundation for hazard free workshop environment and to the acquisition of the right frame of mind for safe working environment. Therefore research should be directed into exploring the levels of awareness among polytechnic students in workshop safety as the findings may provide useful data for drawing up workshop safety initiatives in polytechnics and other tertiary institutions' workshop.

\section{Research Objectives}

The objective of this research was set within this framework:

1. to assess the levels of workshop safety awareness among students in the polytechnics by identifying whether they are familiar with its core themes and issues; and

2. to determine whether students' safety awareness, had an influence on the lack of rampant cases report of injury in school workshop.

A survey was used in this study as it is considered to be a suitable research method for this type of study (Choudrie and Dwivedi, 2006). A self-administered questionnaire comprised the primary survey instrument for data collection, since it addresses the issue of reliability of information by reducing and eliminating differences in the way that the questions are asked, and how they are presented (Fowler, 2002). Furthermore, questionnaires facilitate the collection of data within a short period of time from the majority of respondents, which was a critical issue for this research (Fowler, 2002).

\section{Methodology}

\subsection{Measurement of Awareness}

Awareness is the state of being conscious of ideas or events (Brown \& Ryan, 2003) or the state of realizing that something exists (O’Collins, 2004). A person becomes aware of an idea or event as a result of having heard of it or having come into contact with it through various means, such as through conversations, discussions, watching commercials, reading leaflets, listening to the news, and others. In this study, awareness of workshop safety was defined as students' familiarity with the workshop safety as a result of having heard about it from through class or workshop discussion, reading safety leaflets pasted on the walls, safety warning on the machines, and or though whatever sources. The construct was measured by getting students to rate the levels of their awareness on 15 items of awareness on a 5-point Likert's scale.

\subsection{Population and Sample}

The population of the study consisted of all National Diploma in Engineering courses students of the Hassan Usman Katsina Polytechnic, Nigeria. The sample of the study was National Diploma 11 in Mechanical and Electrical Engineering out of which 130 students were purposively and randomly selected to participate in the survey. All National Diploma 11 Electrical and Mechanical Engineering students were targeted to participate in the survey; therefore every National Diploma 11 student had an equal and likely chance to participate in the survey. The Diploma 11 students were chosen for the study due to the fact that they were final year students, and might have gone into several workshop practices during their Engineering courses. Thus, they were expected to have some experiences in school workshop safety precaution.

\subsection{Instrument}

The study utilised a self-developed safety awareness questionnaire with 15 Likert's-type items that requested students to rate their awareness levels of the items. The response categories used in the study were "High", "Quite High", "Moderate", "Low" and "None." The items were validated by a panel of experts for content properties. The internal consistency of the data for the 15 items was assessed utilising a reliability test (i.e. Cronbach's $\alpha$ ), and was found fit with $\alpha=0.74$, which is very good for an exploratory study, as it is scholarly agreed that reliability should be equal to or above 0.60 (Straub et al. 2004; Golafshani, 2003; Stangor, 2006). 


\subsection{Data Collection and Analysis}

Data were collected by the researcher through questionnaires in class. Students filled them out on the spot and returned them after class. This method ensured $100 \%$ response rate from the students. A total of 130 usable questionnaires were distributed and returned, constituting a response rate of $100 \%$. Analysis of the data involved descriptive statistics (i.e. percentages and frequency counts), computed from the students' responses to the 15 Likert-type items on the awareness of workshop safety precautions using
SPSS version 16.0 for windows.

\section{Result of Study}

The result of the study is presented in tabular form as produced by the SPSS version 16.0, and it is shown below. The result of the descriptive analysis of the 15 items obtained from the SPSS is summated and average percentile scores of the total responses of each item is tabulated as shown in Table 1, while Table 2, shows the mean scores of the item.

Table 1. Summary Descriptive analysis of the 15 items.

\begin{tabular}{|c|c|c|c|c|c|c|c|c|c|c|c|}
\hline \multirow{2}{*}{ Item Description } & \multirow{2}{*}{$\mathbf{N}$} & \multicolumn{2}{|c|}{ None } & \multicolumn{2}{|c|}{ Low } & \multicolumn{2}{|c|}{ Moderate } & \multicolumn{2}{|c|}{ Quite high } & \multicolumn{2}{|c|}{ High } \\
\hline & & fc & $\%$ & fc & $\%$ & fc & $\%$ & fc & $\%$ & fc & $\%$ \\
\hline 1. Type of floor to be used in the in the workshop & 130 & 2 & 1.5 & 2 & 1.5 & 20 & 15.4 & 38 & 29.2 & 68 & 52.3 \\
\hline 2. Machine should be installed with enough space & 130 & 6 & 4.6 & 10 & 7.7 & 38 & 29.2 & 20 & 15.4 & 56 & 43.1 \\
\hline 3. Related operations should be organized & 130 & 12 & 9.2 & 8 & 6.2 & 50 & 38.5 & 28 & 21.5 & 32 & 24.6 \\
\hline 4. First aid box in the workshop & 130 & 12 & 9.2 & 4 & 3.1 & 24 & 18.5 & 32 & 24.6 & 58 & 44.6 \\
\hline 5. Environmental effect of hazardous chemicals & 130 & 20 & 15.4 & 24 & 18.5 & 38 & 29.2 & 26 & 20.0 & 22 & 16.9 \\
\hline 6. Type of protective clothing to be worn in the workshop & 130 & 4 & 3.1 & 4 & 3.1 & 24 & 18.5 & 22 & 16.9 & 76 & 58.5 \\
\hline 8. How fire extinguishers are operated & 130 & 8 & 6.2 & 20 & 15.4 & 28 & 21.5 & 32 & 24.6 & 42 & 32.3 \\
\hline 9. Purpose of sand bucket in the workshop & 130 & 20 & 15.4 & 14 & 10.8 & 24 & 18.5 & 24 & 18.5 & 48 & 36.9 \\
\hline 10. How a sand bucket should be used in the workshop & 130 & 16 & 12.3 & 20 & 15.4 & 18 & 13.8 & 34 & 26.2 & 42 & 32.3 \\
\hline 11. Where the emergency control panel is situated & 130 & 28 & 21.5 & 14 & 10.8 & 38 & 29.2 & 26 & 20.0 & 24 & 18.5 \\
\hline 12. How emergency control panel is switch of & 130 & 26 & 20.0 & 16 & 12.3 & 28 & 21.5 & 24 & 18.5 & 36 & 27.7 \\
\hline 13. The right tool should be used for a job & 130 & 18 & 13.8 & 10 & 7.7 & 22 & 16.9 & 16 & 12.3 & 64 & 49.2 \\
\hline 14. Permission must be sought before using a tool & 130 & 10 & 7.7 & 4 & 3.1 & 28 & 21.5 & 28 & 21.5 & 60 & 46.2 \\
\hline
\end{tabular}

$\mathrm{fc}=$ Frequency count of respondents.

$\%=$ Percentage of respondents.

The result of the analysis (Table 1) indicate that respondents have between moderate and high level of awareness in all the items of workshop safety precautions except in three items, in which majority of the respondents have between low to no level of awareness. These items with low score are, color coding to identify potential danger zone; environmental effect of hazardous chemicals emitted by a machine; and where an emergency control panel is situated.

Table 2. Mean Score of the 15 Item.

\begin{tabular}{|c|c|c|}
\hline Item Description & $\mathbf{N}$ & Mean \\
\hline 1. Type of floor to be used in the in the workshop & 130 & 3.2923 \\
\hline 2. Machine should be installed with enough space & 130 & 2.8462 \\
\hline 3. Related operations should be organized & 130 & 2.4615 \\
\hline 4. First aid box in the workshop & 130 & 2.9231 \\
\hline 5. Environmental effect of hazardous chemicals & 130 & 2.0462 \\
\hline 6. Type of protective clothing that should be worn in the workshop & 130 & 3.2462 \\
\hline 8. How fire extinguishers are operated & 130 & 2.6154 \\
\hline 9. Purpose of sand bucket in the workshop & 130 & 2.5077 \\
\hline 10. How a sand bucket should be used in the workshop & 130 & 2.5077 \\
\hline 11. Where the emergency control panel is situated & 130 & 2.0308 \\
\hline 12. How emergency control panel is switch of & 130 & 2.2154 \\
\hline 13. The right tool should be use for a job & 130 & 2.7538 \\
\hline 14. Permission must be sought before using a tool & 130 & 2.9538 \\
\hline Valid N (listwise) & 130 & \\
\hline
\end{tabular}

The mean score of the fifteen items (Table 2) also shows 3 out of 15 items have high mean scores of 3.29, 3.24 and 3.01 respectively, meaning that majority of the respondents indicated high levels of workshop safety awareness in the type of floor to be used in the workshop; type of protective clothing that should be worn; and never to use a tool or machine until you know how to use it. The overall result of the analysis that indicated students' high level of awareness 
of safety is not unconnected to the fact that each module of the National Diploma in Engineering curriculum starts with an emphasis on safety precaution on that module, and that it has never been compromised by any lecturer to discuss the safety aspect in each module.

\section{Conclusion and Recommendations}

Based on the findings and given the paramount importance of safety precautions in promoting a safe working environment, the study supports this present trend of including safety notes in each module of workshop practice in all technical courses in the polytechnic education in Nigeria. In other words, lecturers and instructors should ensure that awareness and knowledge of workshop safety is well embedded in students through relevant safety discussions and campaign organized by departments and colleges. Departments and colleges can initiate simple yet effective awareness campaigns by putting up posters around the campus, and posting messages in workshops and laboratories. It is further recommended that Instructors should not neglect to buttress the importance of safety measures, whenever they take theirstudents to the workshop, and as such should never hesitate to take a 5-10minutes discussing safety on the module they are going to discussed, so that the record of safe working environment could be maintained

\section{References}

[1] Brown, K. W. \& Ryan, R. M. (2003). The Benefits of being Present: Mindfulness and its role in psychological well-being. Journal of personality and social psychology, 84, 822-848.
[2] Choudrie J., Dwivedi Y. K. \& Brinkman, W. P. (2006) Development of a survey instrument to examine consumer adoption of broadband, Industrial management and data systems, 106, 5, 700-718.

[3] Fowler, F. J. Jr. (2002) Survey research methods, SAGE Publications Inc., London.

[4] Fernandez, T. (1995). Stop in your tracks: an alternative to violence concept media, P. O. Box 19542, Irvine, California, 92623-9542, 800-233-0727.

[5] Golafshani, N. (2003). Understanding reliability and validity in qualitative and quantitative research. Qualitative report, 8 (4), 597-607.

[6] Griffin, W., Montsinger, J. \& Carter, N. (1995). Personal safety handbook: targeting safety in human services. Independent living resources, Inc., 411 Andrews Road, Suite 230, Durham, North Carolina, 27705, 800-820-0001).

[7] Hinton, P. R., Brownlow, C., McMurray, I. \& Cozens, B. (2004). SPSS explained. Routledge Inc., East Sussex, England.

[8] O'Collins, F. (2004). The little book of awareness: An idea about an idea. Australia: UCADIA Books.

[9] Stangor, C. (2006). Research methods for the behavioural sciences $\left(3^{\text {rd }}\right.$ edn $)$. Boston: Hough Mifflin.

[10] Straub, D.; Boudreau, M. \& Gefen, D. (2004). Validation guidelines for IS positive research. Communication of the association for information systems, Vol. 1, No. 1.

[11] Work Solution, (2001). The 7 Things you would better know; Young worker awareness program. Funded by workplace safety insurance board-Ontario. Retrieved from www.yworker.com. 